\title{
LEVANTAMENTO DE MANIFESTAÇÕES PATOLÓGICAS NA PONTE SOBRE O RIO DAS OSTRAS NO MUNÍCIPIO DE BALNEÁRIO CAMBORIÚ, SANTA CATARINA- BRASIL
}

\author{
ANTUNES DE OLIVEIRA, MARJORI \\ Estudante Engenharia Civil \\ Universidade do Vale do Itajaí \\ Santa Catarina; Brasil \\ marjori.oliveira@live.com
}

\author{
DO PRADO PEGORARO, DOUGLAS MAICON \\ Estudante Engenharia Civil \\ Universidade do Vale do Itajaí \\ Santa Catarina; Brasil \\ douglaspradopegoraro@gmail.com
}

\author{
MACHADO FILHO, CARLOS DANIEL \\ Estudante Engenharia Civil \\ Universidade do Vale do Itajaí \\ Santa Catarina; Brasil \\ Carlosdaniel.machado@hotmail.com
}

\author{
DAGNONI NOTARI, GIOVANNA \\ Estudante de Engenharia Civil \\ Universidade do Vale do Itajaí \\ Santa Catarina; Brasil \\ gi_notari@hotmail.com
}

\section{GULAK, DOUGLAS}

Estudante de Engenharia Civil

Universidade do Vale do Itajaí

Santa Catarina; Brasil

douglasgulak@hotmail.com

\author{
VENÂNCIO, CAROLINE \\ Engenheira Civil phD \\ Universidade do Vale do Itajaí \\ Santa Catarina; Brasil \\ caroline.venancio@univali.br
}

\section{RESUMO}

As manifestações patológicas além de afetar a parte estética de uma estrutura em concreto armado, também podem comprometer o aspecto estrutural, submetendo a mesma ao colapso parcial ou até mesmo total. Para o presente estudo, analisou-se uma obra de arte - uma ponte localizada na Rua Manoel Rebelo dos Santos, Balneário Camboriú - SC, sobre o Rio das Ostras. A ponte possui comprimento e largura, respectivamente, de $25 \mathrm{~m}$ e $10 \mathrm{~m}$. Os pilares são de formato circular e apresentam um diâmetro de 1,2 m. Foi realizado um levantamento das manifestações patológicas, suas possíveis e principais causas e origens. As anomalias foram classificadas e se gerou um prognóstico. Com o prognóstico desenvolvido foi traçado um plano de ações corretivas, relacionado à análise das manifestações de maior gravidade e incidência. Por se tratar de uma estrutura com elevado fluxo diário de pessoas, se mostrou fundamental a realização dos reparos propostos pelo trabalho, a fim de adequar os níveis de desempenho dos elementos construtivos que apresentaram problemas, assim sendo possível aumentar a vida útil da ponte. Também foi verificada a importância da realização de manutenções periódicas nos elementos, esta uma das principais ferramentas para colaborar com o não surgimento de manifestações patológicas futuras, atuando de maneira preventiva dentro desta ciência conhecida como Patologia.

Palavras-chave: ponte, manifestações patológicas, estudo de caso.

\begin{abstract}
Pathological manifestations, besides affecting the esthetics part of a reinforced concrete structure, can also compromise the structural performance, subjecting it to partial or to total collapse. For the present study, it was analyzed a work of art - a bridge located at Manoel Rebelo dos Santos street, Balneário Camboriú - SC, over the Ostras River. The bridge has a length and width of $25 \mathrm{~m}$ and $10 \mathrm{~m}$ respectively. The columns are circular and have a diameter of $1.2 \mathrm{~m}$. It was realized the pointing of the pathological manifestations, their possible and main causes and origins. The anomalies were classified, and a prognosis was generated. With the prognosis developed, a corrective action plan was drawn up, related to the analysis of the manifestations of higher severity and incidence. Because it is a structure with high daily flow of people, it was essential the execution of the repairs proposed by the work, in order to adjust the performance levels of the constructive elements that presented problems, thus, the intervention increases the bridge's service life. It was also verified the importance of performing periodic maintenance on the elements, one of the main tools for collaboration with the nonappearance of future pathological manifestations, acting preventively within this science known as Pathology.

Keywords: bridge, pathological manifestations, case study.
\end{abstract}




\section{INTRODUÇÃO}

No Brasil, devido à carência de manutenções preventivas e/ou corretivas em Obras de Artes Especiais (OAE's), as estruturas apresentam manifestações patológicas preocupantes. As manifestações patológicas, além de afetar a parte estética, também podem comprometer o aspecto estrutural, submetendo a mesma a um colapso parcial ou até mesmo total. A falta de manutenção faz com que patologias de baixo custo de recuperação evoluam, agravando a parte estética da obra, tornando-a insegura e de alto custo para recuperá-la. Deste modo, as manutenções adequadas são imprescindíveis para garantir a vida útil das OAE's.

No presente estudo, por se tratar de uma obra de aproximadamente 52 anos, levou-se em consideração a grande dimensão da seção transversal dos pilares, juntamente com seu pequeno comprimento, logo, podemos dizer que se trata de um elemento com baixa esbeltez. Segundo a NBR 6118:2014, o índice de esbeltez é a razão entre o comprimento de flambagem e o raio de giração, nas direções a serem considerada. Portanto, podemos dizer que um elemento mais esbelto tende a apresentar maior movimentação e, consequentemente, maior é a probabilidade de haver fissuras e entrada de elementos agressivos nos materiais. Dessa forma, por consequência da baixa esbeltez, a velocidade de degradação dos mesmos se torna mais lenta.

\section{METODOLOGIA}

O presente trabalho caracteriza-se pelo estudo de caso realizado em uma obra de arte - ponte localizada na Rua Manoel Rebelo dos Santos, 1492-1936, Bairro da Barra, Balneário Camboriú - SC, sobre o Rio das Ostras. A ponte possui comprimento e largura, respectivamente, $25 \mathrm{~m}$ e $10 \mathrm{~m}$. Os pilares são no formato circular e de diâmetro $1,2 \mathrm{~m}$. O cobrimento das armaduras destes pilares é de $1,5 \mathrm{~cm}$. A ponte possui uma idade de aproximadamente 52 anos, em que reformas e reparos foram realizados de forma superficial até o presente momento.

Para os autores terem conhecimento dos detalhes construtivos foram realizadas duas entrevistas, uma com o engenheiro civil aposentado pela prefeitura municipal e outra com o ex-funcionário da prefeitura que acompanhou o processo de construção da ponte. Também foram efetuadas duas vistorias na obra de arte para coleta dos dados e levantamento das manifestações patológicas, essas duas ações foram feitas em conjunto, de modo a tirar quaisquer dúvidas que surgissem ao longo das vistorias. Posteriormente, as manifestações patológicas foram classificadas e realizou-se um prognóstico. Por fim foi estimado um plano de ação para correção das anomalias.

\subsection{Vistoria e Diagnóstico}

As vistorias foram realizadas no mês de outubro de 2018. O Engenheiro Civil Tarcísio Notari e o mestre de obras Oswaldo René, acompanharam a visita e contribuíram com informações relevantes da obra. Uma inspeção fotográfica foi realizada para a descrição das manifestações patológicas.

A ponte localiza-se sobre via hídrica, ou seja, os agentes patológicos são de espécie agressiva. Segundo a Empresa Municipal de Água e Saneamento (EMASA) o $p H$ da água do local fica próximo à 7 , média obtida por dados do mês de janeiro a julho de 2018. A ponte também está localizada na foz do rio das Ostras, logo, neste local há grande influência das marés e águas salinas. 

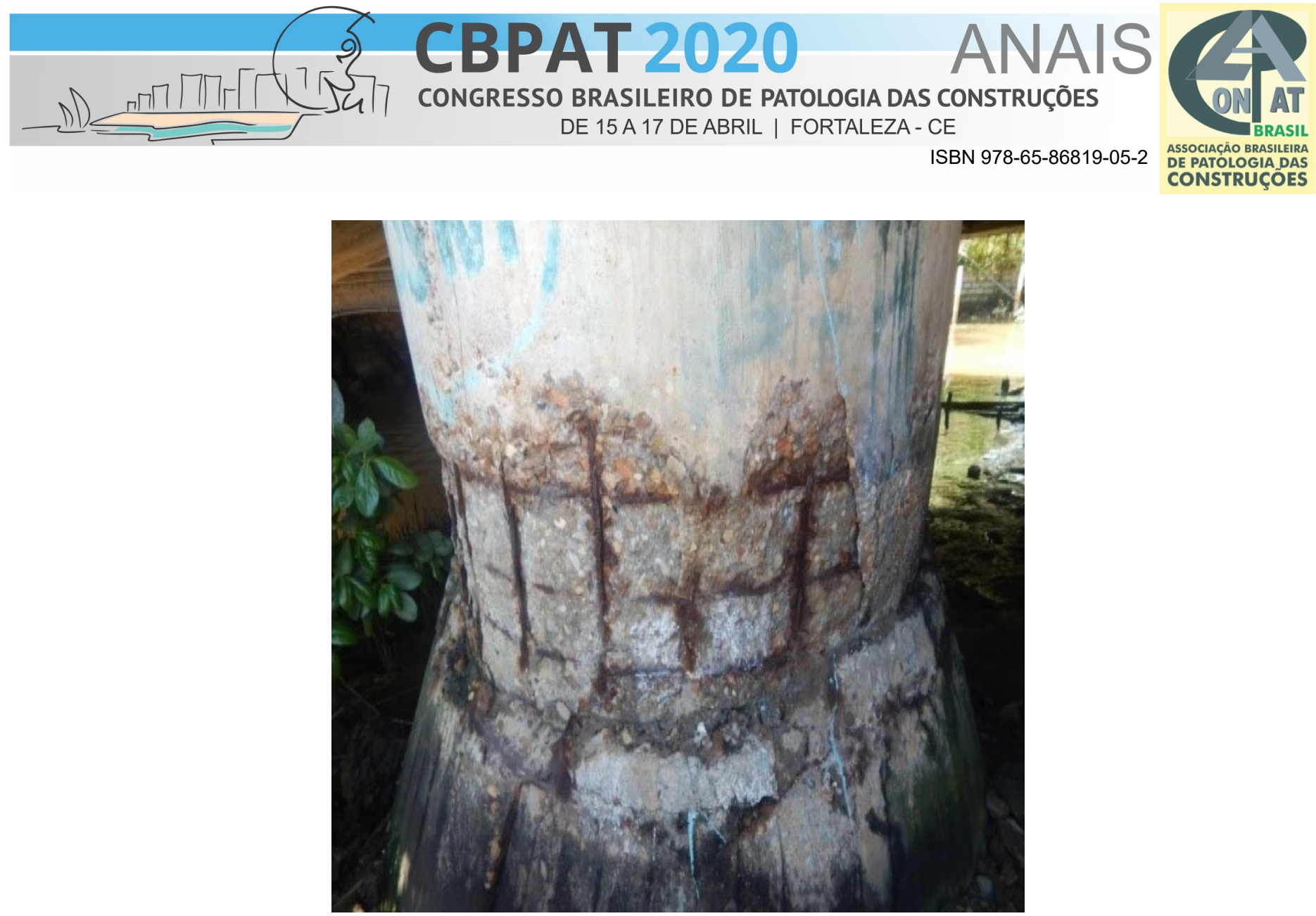

Figura 1:Desagregação do concreto e avançado estado de corrosão das armaduras do pilar de sustentação da ponte.

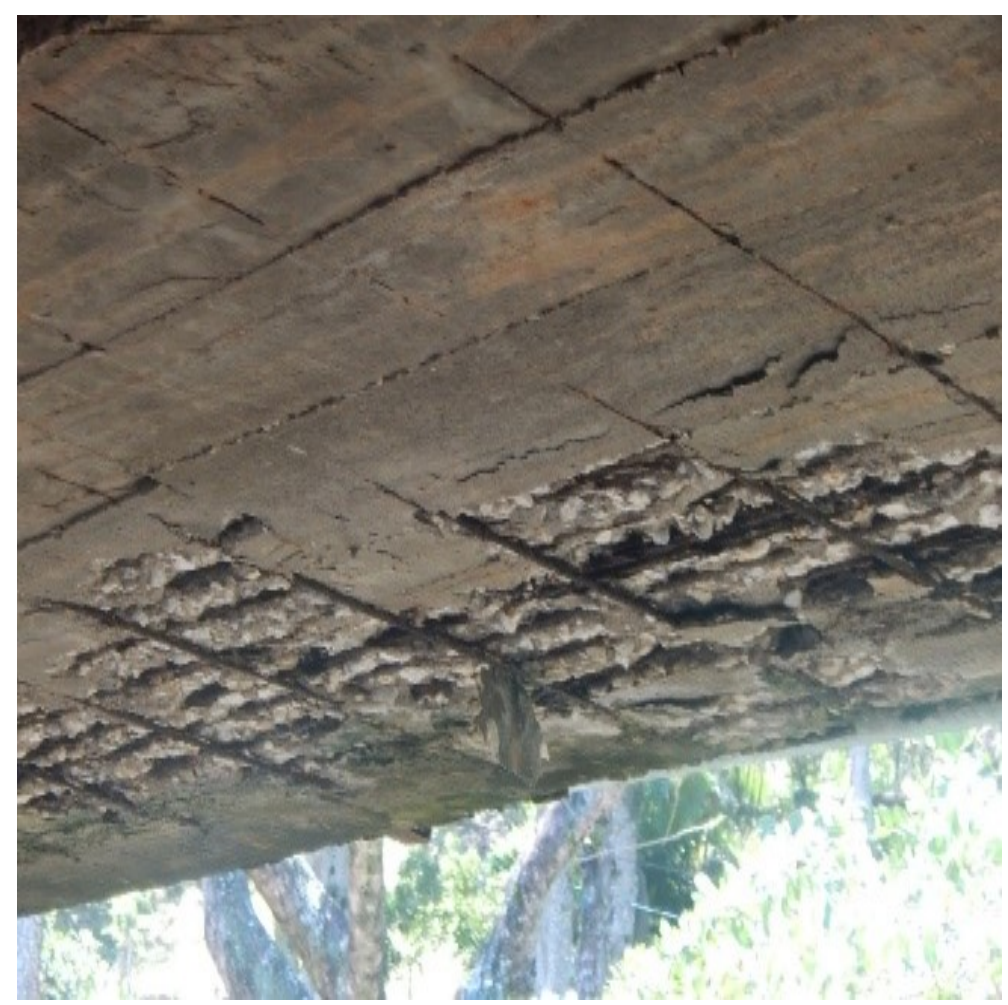

Figura 2: Perda de cobrimento do concreto e armaduras em avançado estado de corrosão nas vigas longarinas. 

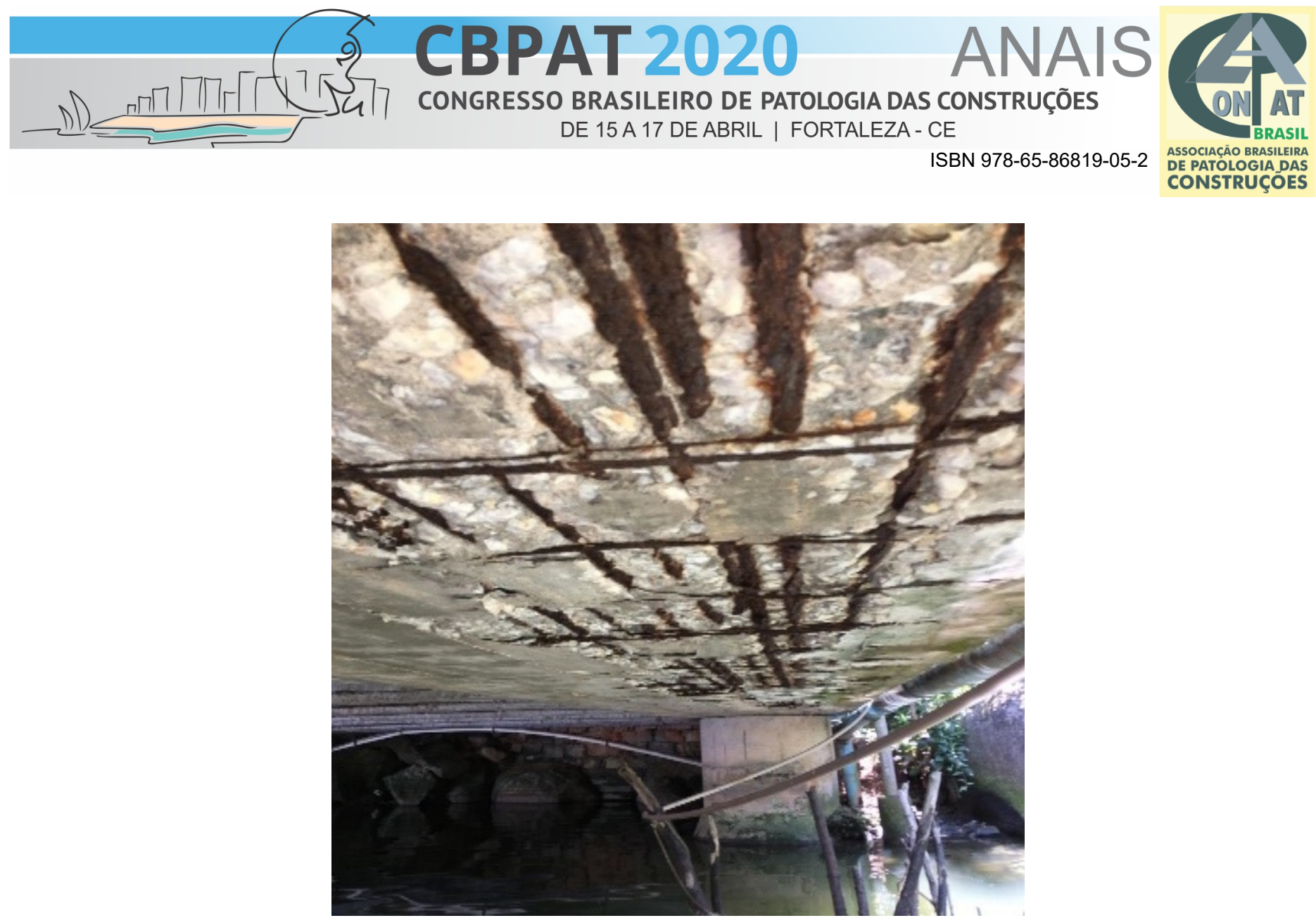

Figura 3: Perda de cobrimento do concreto e armaduras em avançado estado de corrosão nas longarinas.

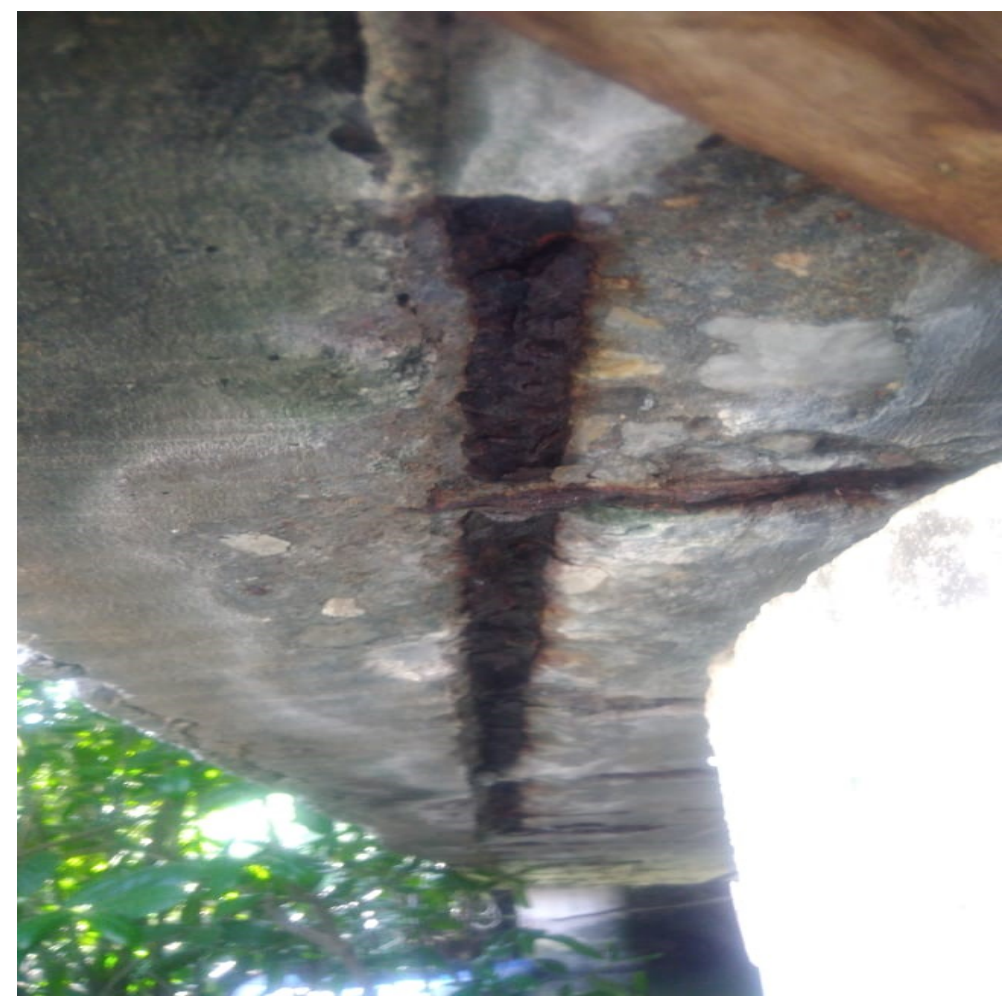

Figura 4: Corrosão das armaduras ao longo da viga longarina e cobrimento das armaduras longitudinais insuficientes. 


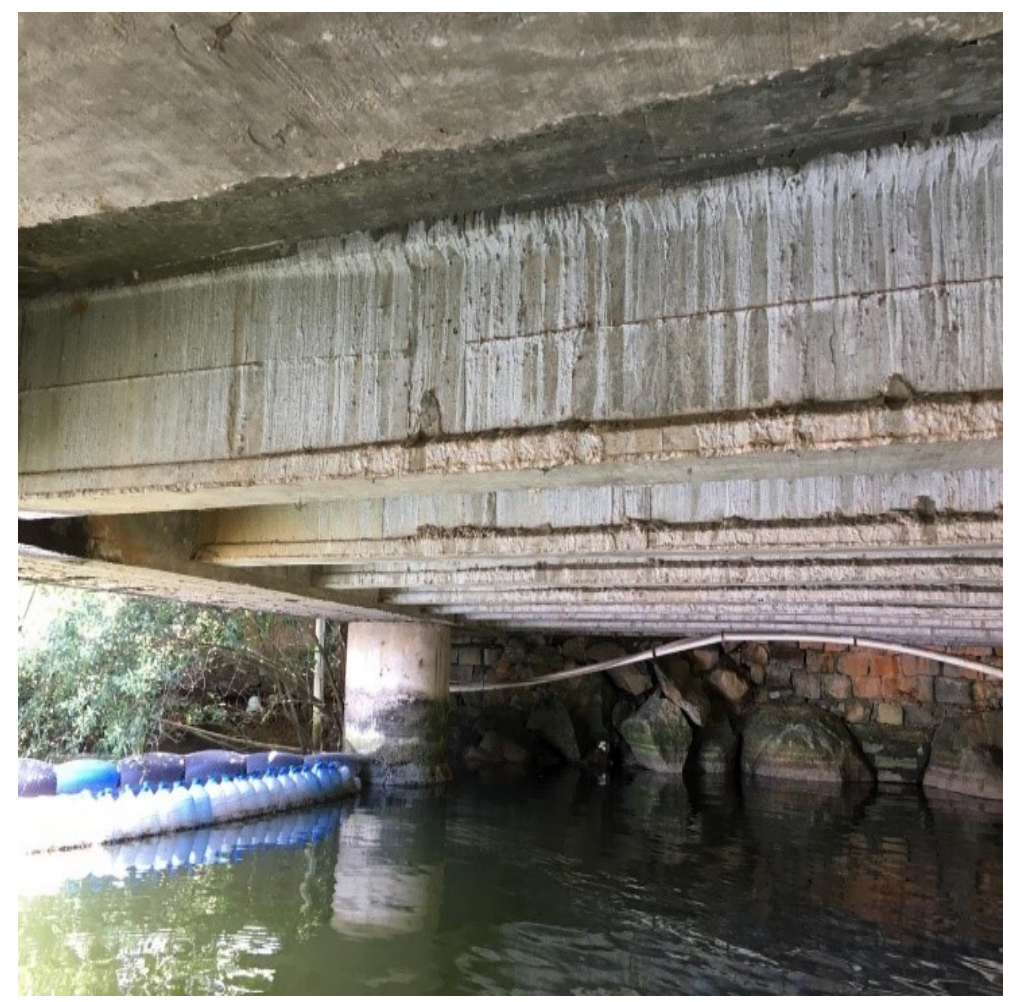

Figura 5: Presença de eflorescência nas transversais.

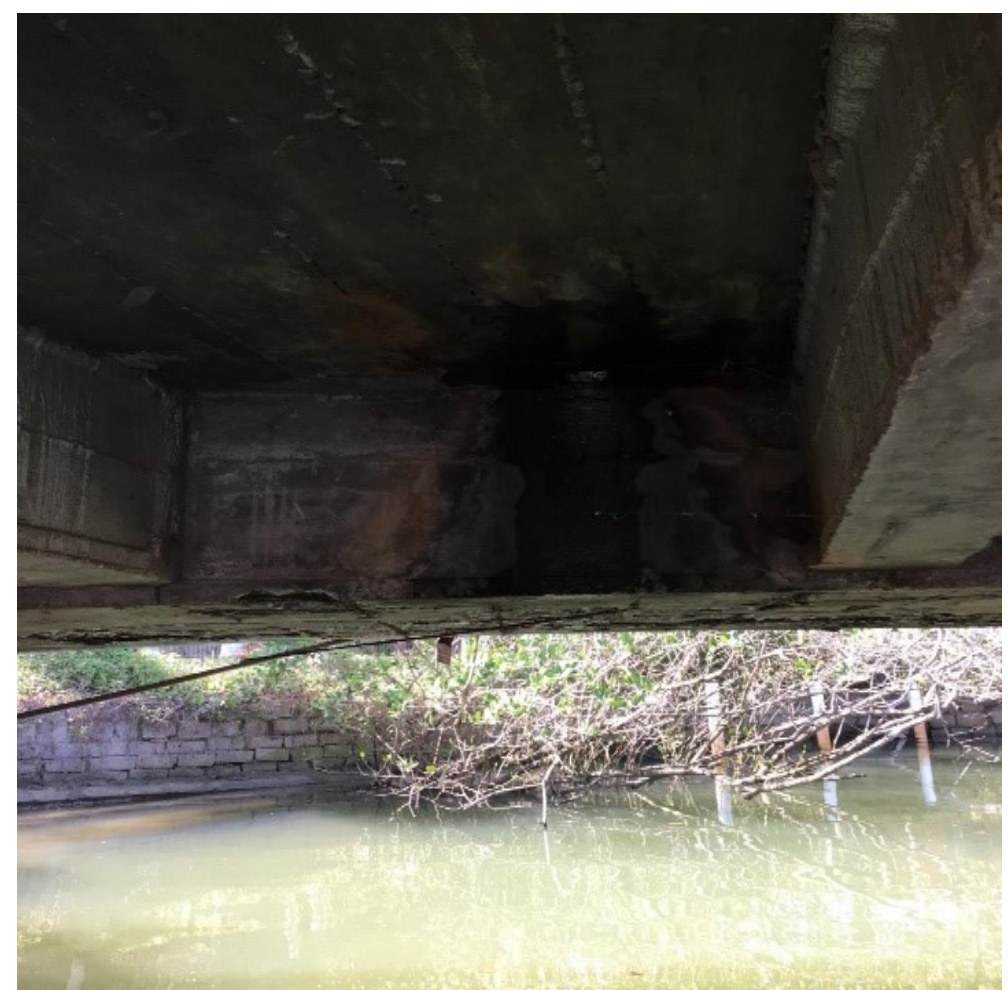

Figura 6: Presença de eflorescência e infiltração de água sobre as longarinas. 

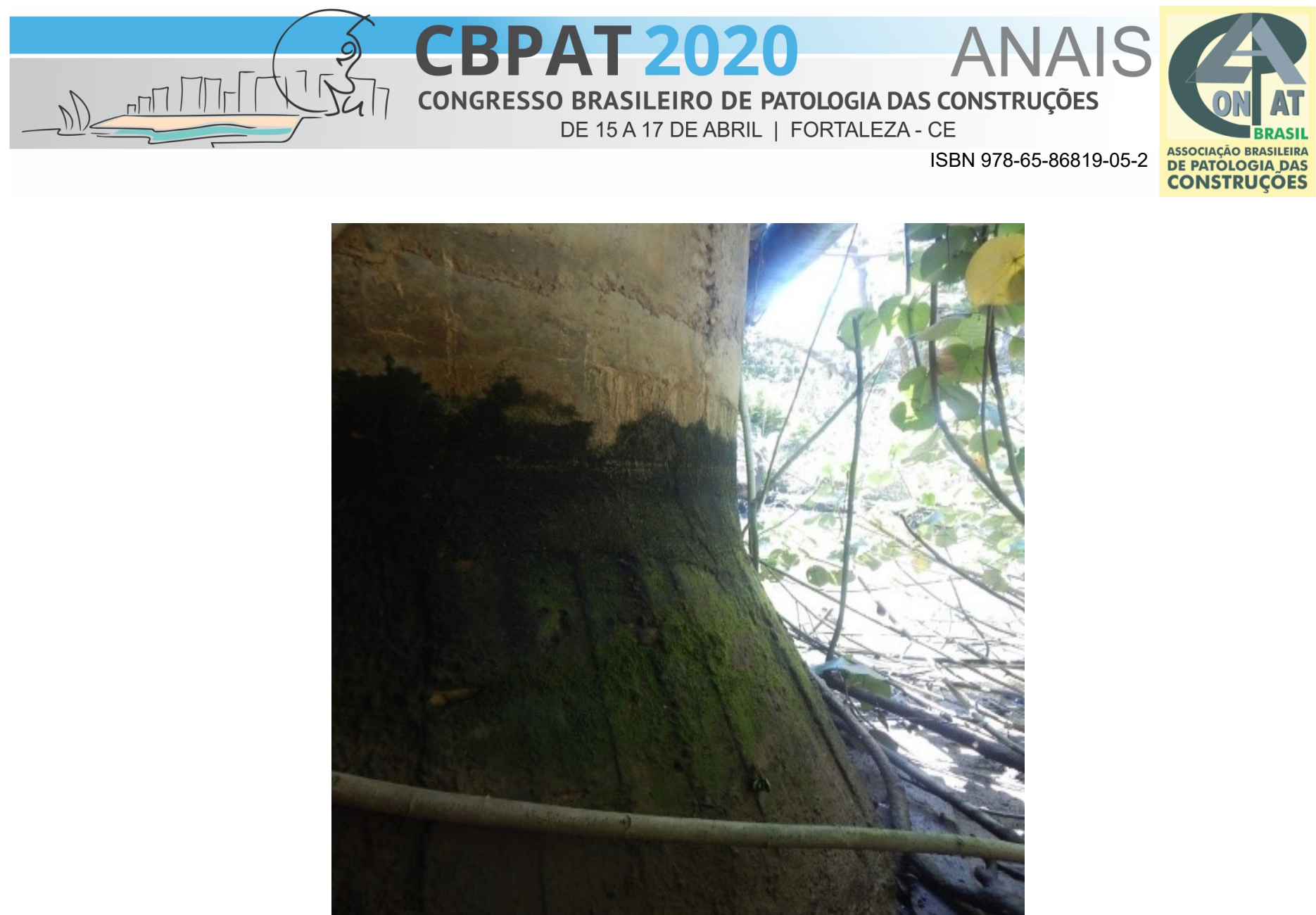

Figura 7: Formação de musgo sobre a superfície do concreto do pilar traseiro.

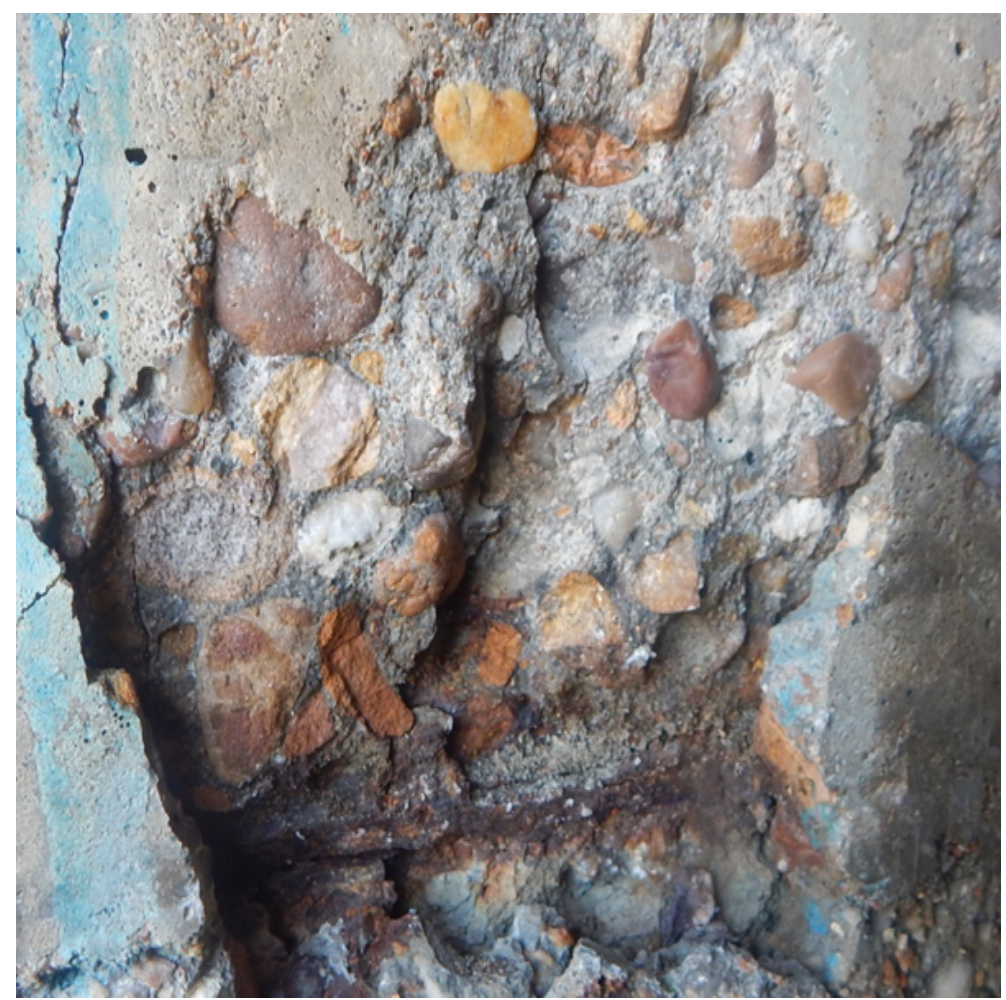

Figura 8: Aparecimento dos agregados utilizados na composição do concreto. 


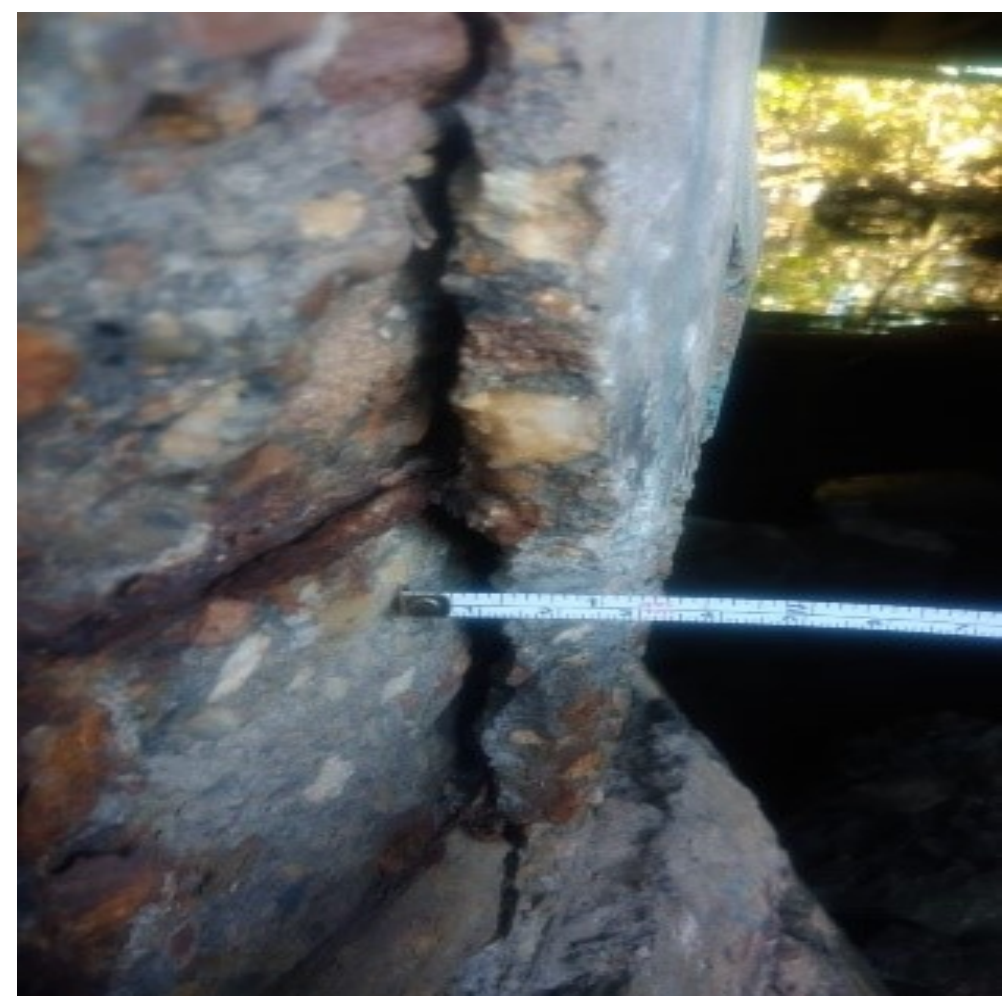

Figura 9: Perda de $3 \mathrm{~cm}$ de cobrimento das armaduras do pilar.

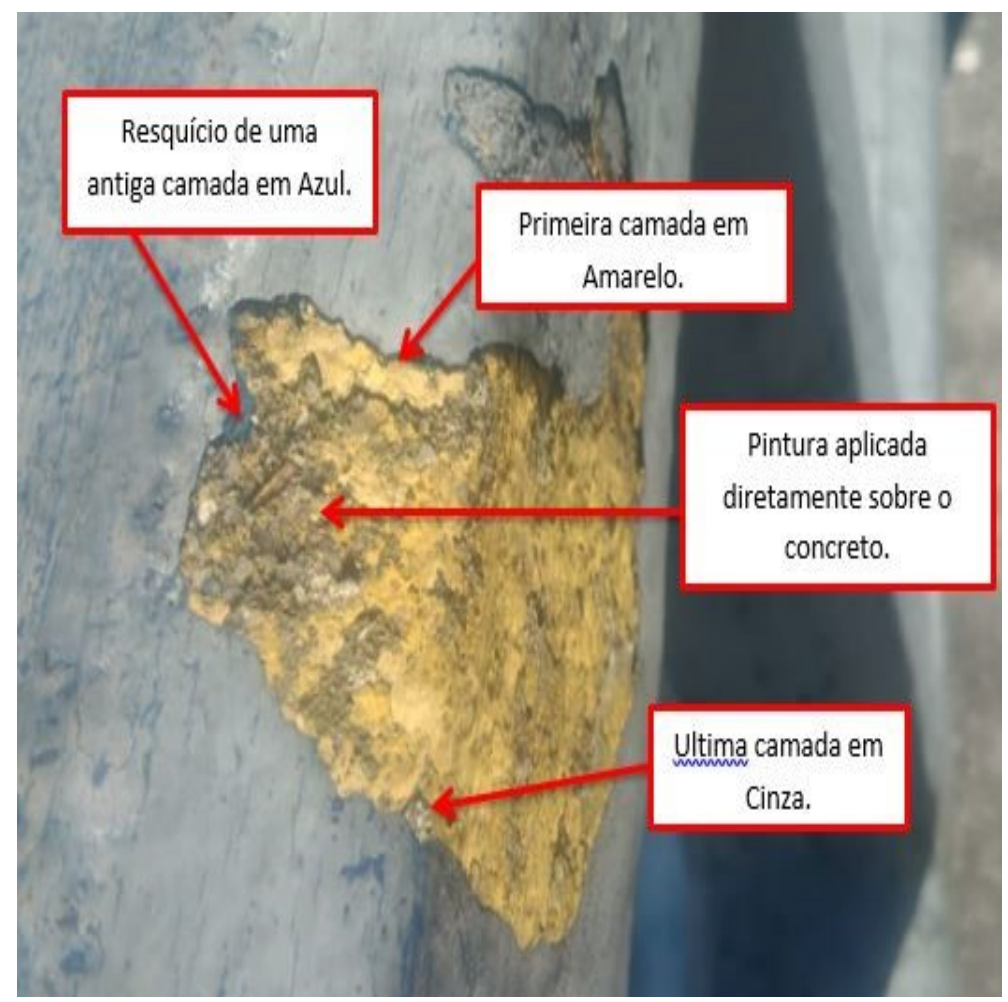

Figura 10: Descascamento da pintura dos guarda corpos. 


\section{CBPAT 2020

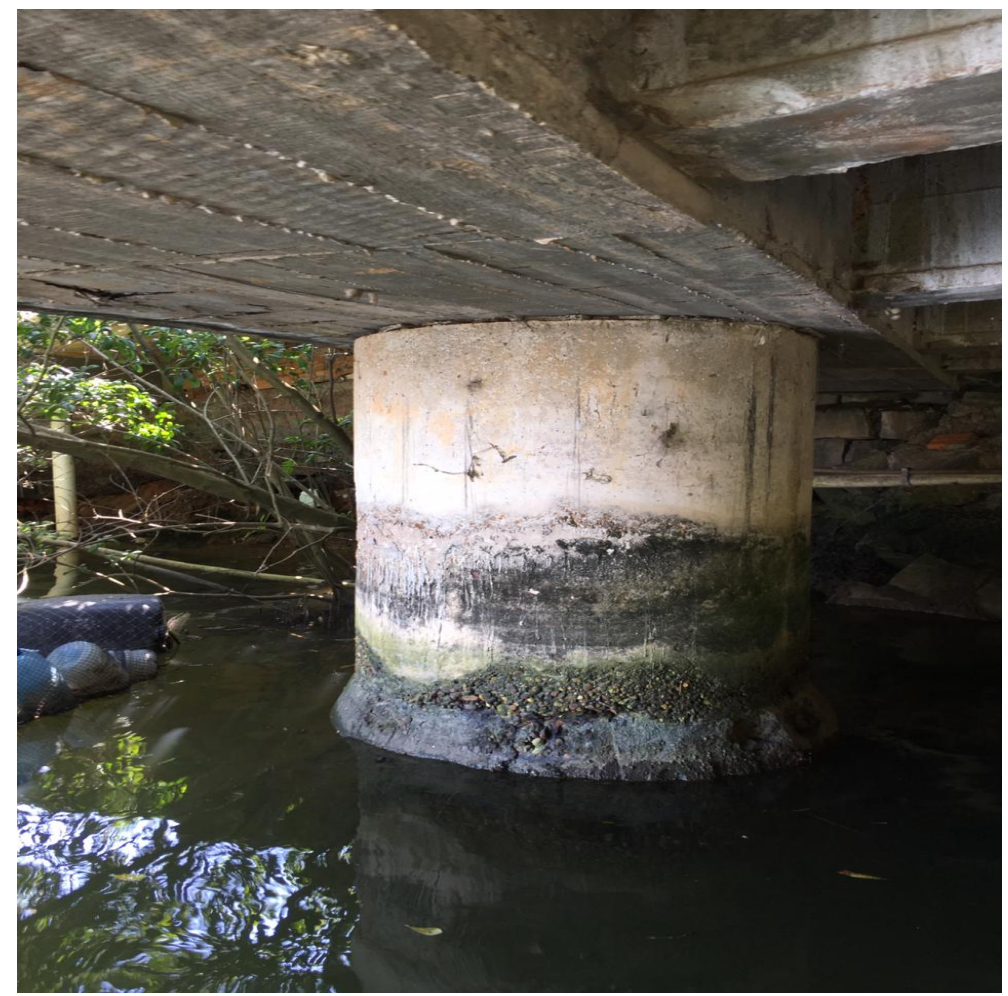

Figura 11: Aparelho de apoio rígido.

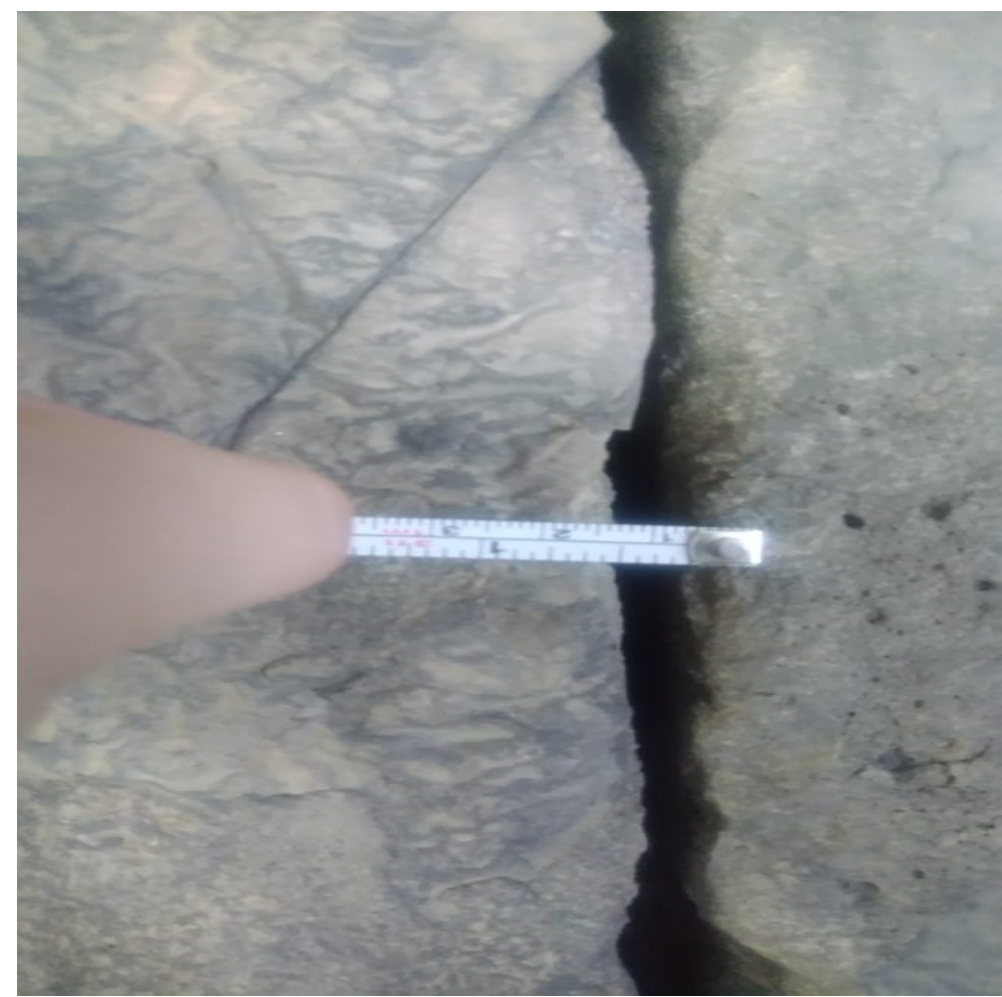

Figura 12: Junta de dilatação inexistente e abertura da mesma de aproximadamente $3 \mathrm{~cm}$.

\subsection{Manifestações Patológicas}

Após realizada a vistoria in loco, foi feita a classificação das anomalias a fim de obter a quantidade de ações a serem tomadas e também para detetar o grau em que cada uma se encontra. As anomalias se classificaram em três grupos, sendo 
eles: Crítico, Regular e Satisfatório. Diante desta classificação, conforme Tabela 1, pode-se avaliar qual anomalia necessita de imediata intervenção para se evitar uma deterioração ainda mais precoce.

\begin{tabular}{c|c|c|c}
\hline \multirow{2}{*}{ Anomalias } & \multicolumn{3}{|c}{ Classificação das anomalias } \\
\cline { 2 - 4 } & Crítico & Regular & Satisfatório \\
\hline Corrosão da armadura & $\mathrm{X}$ & $\mathrm{X}$ & \\
\hline Desagregação do concreto & - & $\mathrm{X}$ & $\mathrm{X}$ \\
\hline Lixiviação & - & - & $\mathrm{X}$ \\
\hline Eflorescência & - & - & $\mathrm{X}$ \\
\hline Fissuras & - & - & $\mathrm{X}$ \\
\hline Descascamento da pintura & - & - & $\mathrm{X}$ \\
\hline Falta de juntas de amortecimento & $\mathrm{X}$ & - & - \\
\hline Falta de juntas de dilatamento & $\mathrm{X}$ & - & - \\
\hline Trincas & $\mathrm{X}$ & $\mathrm{X}$ & $\mathrm{X}$ \\
\hline
\end{tabular}

Tabela 1: Classificação das anomalias.

O Gráfico abaixo traz um panorama geral em relação a classificação dos tipos de anomalias encontradas na obra de arte, informando a percentagem de cada classificação em relação à todas as manifestações levantadas.

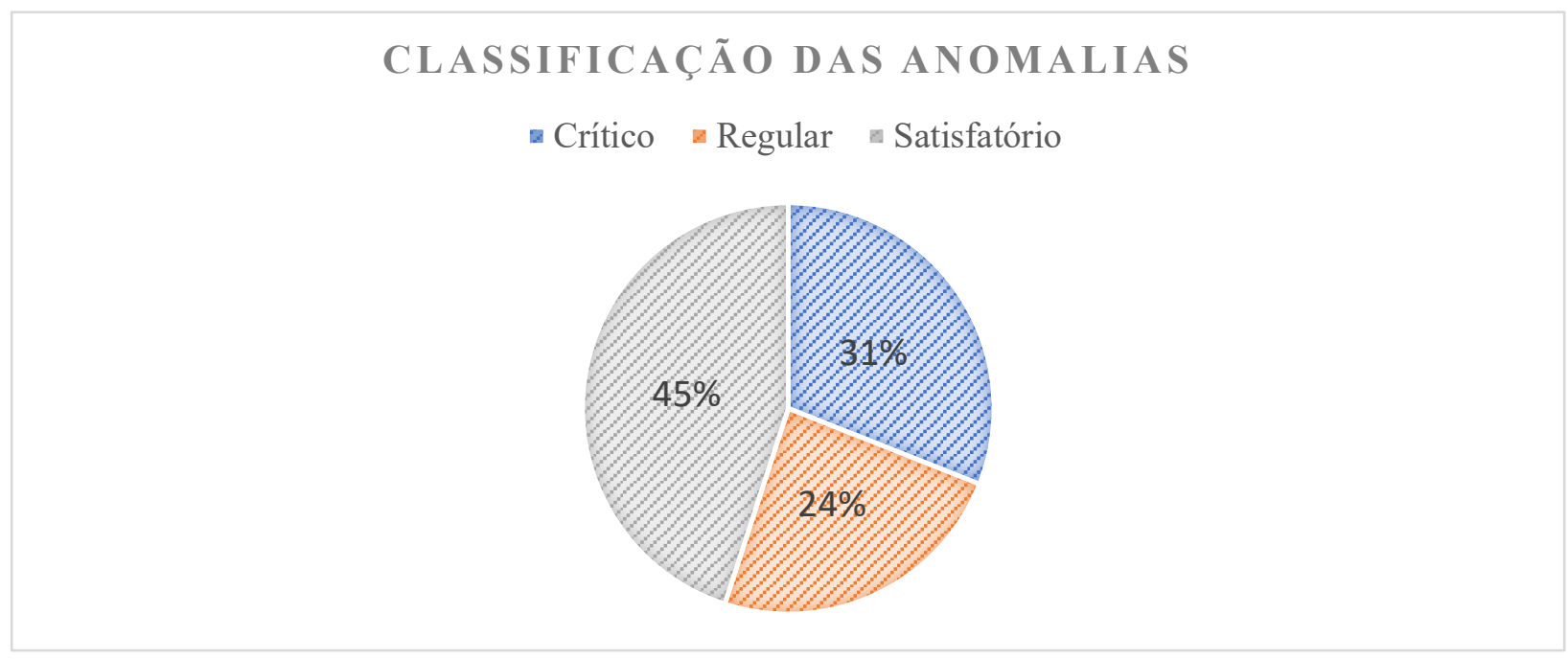

Gráfico 1: Anomalias encontradas.

Conforme representado no Gráfico 1, é possível visualizar que prevaleceu o grau satisfatório, contabilizando $45 \%$ das anomalias encontradas. Apesar do estado crítico ter percentagem inferior ao satisfatório, sendo 31\%, sua percentagem é preocupante, fazendo-se necessário buscar medidas a fim de não agravar ainda mais as anomalias. Na Figura 17 foi desenvolvida uma planta baixa com as disposições das manifestações patológicas encontradas na respectiva obra de arte. 


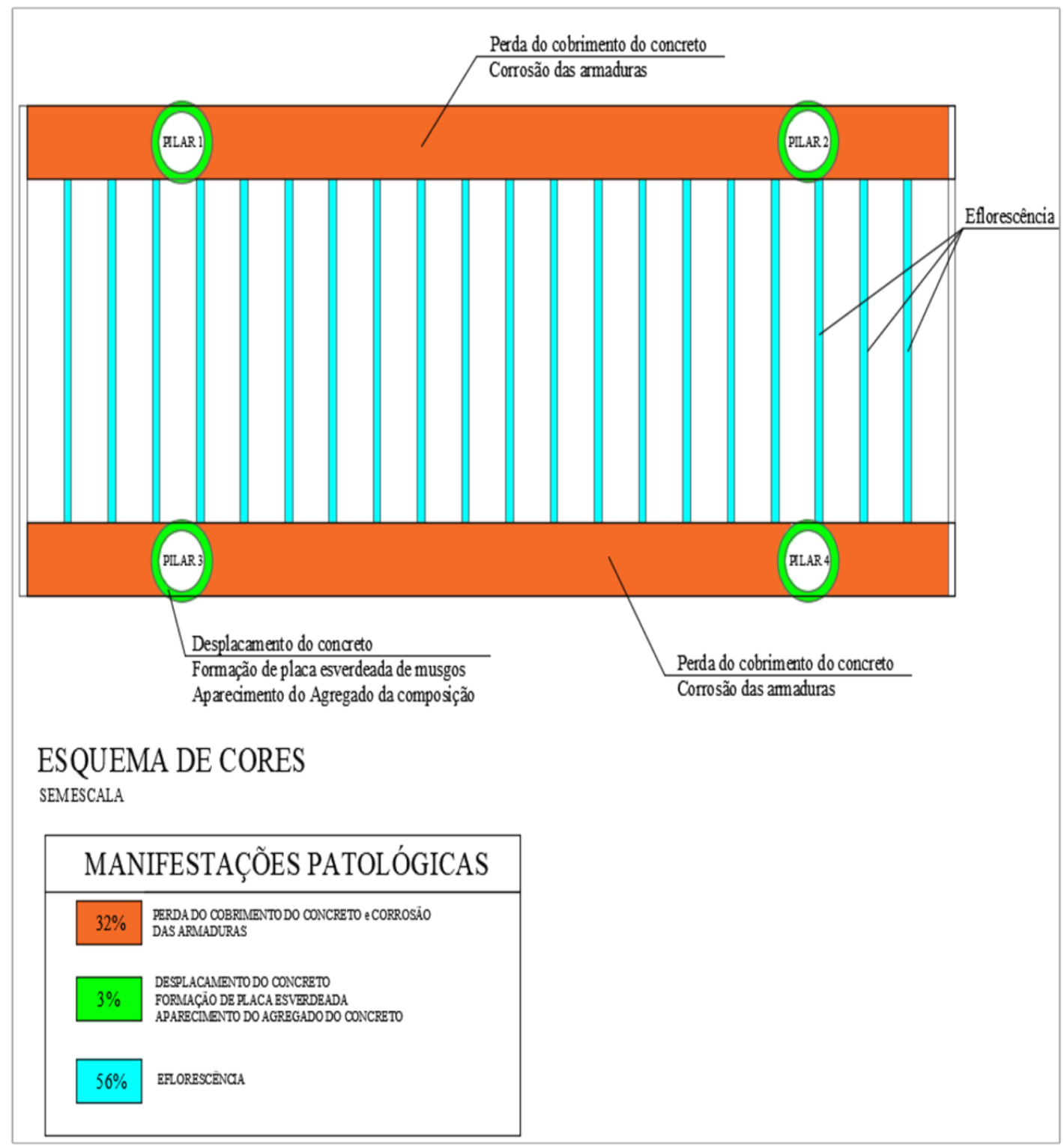

Figura 13: Representação das manifestações patológicas na ponte.

\subsection{Prognóstico}

Com relação às manifestações patológicas visualizadas na obra de arte, foram estimadas as seguintes previsões de sua evolução:

a) Corrosão das armaduras: Conforme ilustrado nas Figuras 1, 2, 3 e 4, as regiões que mais sofrem com a corrosão das armaduras são as longarinas e os pilares de sustentação da ponte. Os pilares possuem desplacamento do concreto e rompimento das armaduras em diversos pontos. Como apresentado na fase de diagnósticos, as manifestações patológicas mesmo intensas não apresentam risco de colapso, uma vez que resiste sem reparos há aproximadamente 52 anos. No entanto, caso continue sem reparos, a corrosão pode se tornar cada vez mais intensa e atingir ainda mais o interior da estrutura, principalmente por haver grande área de aço em processo de corrosão, o que acaba acelerando a contaminação das demais áreas. Assim, com a corrosão mais interna, haverá a diminuição da área efetiva de armadura e submetendo a estrutura em risco de colapso. Os pilares com maiores níveis de degradação são os pilares 1 e 2, conforme esquematizado na Figura 13, os quais estão voltados para a foz do Rio das Ostras, por este motivo sofrendo ainda mais com a maresia. No mesmo, encontra-se perda de seção das armaduras e, também, pontos em que já ocorre a inexistência da mesma, por este motivo se torna o elemento com maior urgência de recuperação. 
b) Desagregação do concreto: A desagregação do concreto ocorre principalmente pela expansão do aço, levando ao desplacamento do concreto em diversos pontos de uma estrutura. Por consequência, aumenta o processo de corrosão das armaduras e diminui ainda mais a capacidade do elemento de resistir aos esforços que as solicitam. Com relação à obra de arte vistoriada, conforme representado na Figura 9, pode-se prever que futuramente esta manifestação patológica auxiliará na inexistência do cobrimento necessário para as armaduras, gerando corrosões mais críticas e profundas, podendo levar a estrutura ao colapso, uma vez que ambas as manifestações atuam de forma subsequentes.

c) Lixiviação e Eflorescência: Estas duas manifestações patológicas se encontram descritas em um mesmo tópico, pois há diversas similaridades entre elas, por vez suas consequências seguem um mesmo caminho lógico. Um dos motivos para que ocorra a lixiviação é a utilização de cimentos puros, ou seja, sem nenhum aditivo, o que pode ter sido uma das causas observadas, uma vez que a obra é antiga e na época não se utilizava destes recursos. Conforme ilustrado na Figura 5 e 6, observa-se que a maior preocupação com ocorrência das mesmas é a estética. Porém, quando o mesmo se atinge níveis avançados, podem-se abrir caminhos para a entrada de soluções mais nocivas, levando a corrosão do aço e concreto. Desse modo, deve-se haver uma correção deste manifesto, a fim de não agravar ainda mais a situação já existente na estrutura.

d) Descascamento da tinta: A pintura geralmente atua como proteção da base em que se localiza, evitando que agentes químicos e agressivos entre em contato com a peça. Uma vez que esta proteção está falha, a base de concreto ficará exposta a agentes agressivos do meio, como cloretos e sulfatos, podendo acarretar na corrosão do concreto. Na Figura 10 se observa a necessidade de reparos nos guarda corpos, a fim de prolongar a vida útil do elemento.

e) Aparelhos de apoio: Os aparelhos de apoios são destinados a transmitir as cargas do tabuleiro aos pilares e encontros, libertando ao mesmo tempo outras componentes dos esforços/deslocamentos, como por exemplo, as rotações. De acordo com a ilustração da Figura 11, os aparelhos de apoio são do tipo rígido, não permitindo as restrições de movimentos e mesmo se tratando de uma estrutura antiga e com vão médio, não apresenta indícios de manifestações patológicas acarretadas pelos aparelhos de apoio existente. Embora os aparelhos de apoio não causem nenhuma manifestação patológica diretamente na estrutura, o fato de o mesmo se tratar de apoio rígido feito de madeira, um material que absorve umidade e a mantém por mais tempo que o concreto, pode agravar o problema já existente de corrosão do concreto, gerando assim uma causa para uma futura manifestação patológica.

f) Junta de Dilatação: As juntas de dilatação são elementos colocados nas interrupções estruturais do tabuleiro, de modo a permitir os movimentos causados pela variação de temperatura, retração e fluência do concreto. Também servem para garantir a estanqueidade, não permitindo a infiltração de água para a estrutura. Conforme Figura 12, constata-se que não há vedação na junta de dilatação, o que causa infiltração no tabuleiro, trazendo como consequência todas as patologias decorrentes desse fato.

\subsection{Plano de ações corretivas das anomalias}

A recuperação de uma estrutura de concreto armado envolve, além da investigação das causas da patologia, a especificação de materiais adequados para a ação corretiva, bem como as boas práticas executivas. Para a recuperação das manifestações patológicas encontradas, são recomendados os seguintes serviços de recuperação:

\section{a) Corrosão das armaduras}

As etapas executivas para a recuperação dos pilares e longarinas da obra de arte devem seguir a seguinte sequência:

1) Exposição completa da barra através da remoção do concreto envolvente eventualmente já desagregado nas circunvizinhanças. Nesta etapa, faz-se necessário a remoção das partes do concreto soltas e retirada de resíduos de poeira, tinta e óleos que possam prejudicar a aderência dos produtos de recuperação estrutural. Para a remoção das partes soltas de concreto, faz-se através de um apicoamento, de maneira a obter uma superfície rugosa. As poeiras ocasionadas pelo apicoamento devem ser retiradas através de um jateamento de água e ar, e os óleos devem ser retirados através de solventes.

Segundo HELENE (1992), para a situação em que a armadura e o concreto se encontram em meio úmido, o melhor meio para a preparação do substrato seria por meio de disco de corte e remoção de óleos e graxas impregnadas. 
- Disco de corte: Método utilizado para delimitar o contorno da área de reparo com o uso da máquina de corte com disco diamantado. O corte deve ser feito em profundidade de pelo menos $2 \mathrm{~cm}$ ou o diâmetro das barras.

- Remoção de óleos e graxas: Método utilizado após o uso do disco de corte para a limpeza do substrato.

2) Limpeza da armadura mediante lixamento manual ou com aplicação de escova de aço. Esta operação de limpeza tem por objetivo remover a camada de óxido solta ou semisolta do contorno da barra.

3) Em seguida, faz-se a passivação da mesma com primer anticorrosivo de base cimentícia ou epóxi. A aplicação da pintura anticorrosiva deve ser feita com, no mínimo, duas demãos, ou conforme especificado pelo fabricante. Posteriormente, deve-se criar uma ponte de aderência com a nova armadura que será disposta.

O método para recuperação da corrosão nas longarinas segue a mesma sequência que os pilares, com o único diferencial de nas mesmas não ter sido encontrado perda da seção total da armadura, de mesmo modo, como o aço já se encontra em processo de corrosão estas partes devem ser eliminadas e substituídas, uma vez que a corrosão pode contaminar outras partes da estrutura.

\section{b) Desagregação do concreto}

Conforme comentado anteriormente, à desagregação do concreto possivelmente ocorreu devido à expansão da área das armaduras. Portanto, para a correção da desagregação do concreto, deve-se empregar uma nova camada de argamassa ou concreto de alta resistência, respeitando o cobrimento de $5 \mathrm{~cm}$, mínimo exigido pelas normas atuais para áreas marítimas. Como o meio em que se encontra a obra é de extrema agressividade, o mais ideal seria a utilização de concreto com composto resistente a sulfatos. De modo a facilitar ainda mais o processo de execução, utiliza-se a aplicação do material por meio de projeção. Esta etapa consiste na aplicação do material por meio de jato, onde a velocidade do mesmo faz com que o material comprime na superfície de base e, assim, excluindo a necessidade de fôrmas de madeira.

\section{c) Lixiviação e Eflorescência}

No grau que se encontra esta manifestação patológica na obra de arte, não necessita de grande reparo, uma vez que o problema causado pela mesma é apenas estético. Porém, recomenda-se um leve jateamento de água de maneira a retirar as manchas esbranquiçadas na superfície do concreto das vigas longarinas e transversinas. Nos casos em que os sais se tornam insolúveis, sugere-se a retirada por meio de soluções diluídas em água.

\section{d) Descascamento da tinta}

Uma forma simples de recuperação da pintura dos guarda corpos é a remoção da camada de tinta atual e a repintura com preparação da base. Foi possível observar na obra de arte que certos pontos do guarda corpo sofrem com a deterioração também do concreto. O sugerido para tal então seria, primeiramente, a recuperação dessas áreas com argamassa de alta resistência; posteriormente, faz-se o lixamento e a aplicação de tinta a base de epóxi, a fim de garantir maior proteção dos guarda corpos contra agentes nocivos ao concreto e armaduras, uma vez que o ambiente é úmido e agressivo.

\section{e) Aparelhos de apoio}

Os aparelhos de apoio, mesmo não comprometendo a estabilidade estrutural da obra, indiretamente podem estar ligados a corrosão de algumas peças. Sendo assim a troca deste material por um aparelho de apoio de elastômero seria a melhor solução para os problemas encontrados. Para tal é necessário que se faça o levantamento da mesa da ponte por meio de macaco hidráulico, retirando-se o aparelho de apoio existente e fazendo a substituição pelo novo, afim deste não absorver umidade em excesso e evitar a corrosão em seu entorno.

\section{f) Inexistência de Junta de Dilatação}

Com relação à inexistência de junta de dilatação, esse problema acaba facilitando a infiltração de água para os elementos abaixo da pista de rolamento e auxiliando na deterioração das transversinas e longarinas. Para resolver o problema, o ideal seria a limpeza das juntas e a colocação de um selante de material EDM (etileno propileno dieno monômero), de modo a impermeabilizar e permitir as movimentações da estrutura. 


\section{CONCLUSÕES}

O presente estudo avaliou e vistoriou uma obra de arte - ponte, a fim de avaliar suas manifestações patológicas. Foi realizado o levantamento das principais anomalias, que por sua vez comprometem a vida útil da estrutura, bem como prejudicam sua esbeltez e seu desempenho funcional e estrutural.

Como foi apontado, podem ser inúmeras as causas e origens dos problemas patológicos que se encontram na estrutura. Podendo estas estar ligadas a diferentes origens, seja na fase de projeto, como a não utilização de materiais adequados, na má execução de uma técnica construtiva ou durante a utilização da estrutura. Ficou claro que as causas podem ser variadas, passando por problemas na constituição química dos materiais, erros humanos, tanto no projeto como execução, devido à negligência ou falta de qualidade, até ataques biológicos e de agentes agressivos às armaduras e ao concreto.

Através do laudo demonstrando as manifestações patológicas, foram exemplificadas formas e técnicas para correção das patologias a fim de garantir um desempenho eficiente da estrutura.

Por se tratar de uma estrutura com elevado fluxo de pessoas diariamente, mostra-se fundamental a realização dos reparos propostos pelo trabalho, a fim de adequar os níveis de desempenho dos elementos construtivos que apresentaram patologias, fazendo com que se tenha um aumento de vida útil da ponte. A importância de realização de manutenções periódicas nos elementos, também se mostra uma das principais ferramentas para colaboração com o não surgimento de manifestações patológicas futuras na estrutura.

\section{REFERÊNCIAS}

ANBR, Associação Brasileira de Normas Técnicas. NBR 6118: Projeto de Estruturas de Concreto Armado Procedimento. Rio de Janeiro, 2014.

HELENE, P. R. L. Manual para reparo, reforço e proteção de estruturas de concreto. 2. ed. São Paulo: Pini, 1992.

HELENE, P. R. L. Corrosão em armaduras para concreto armado. São Paulo, SP: Pini, 1986.

MIRANDA, M. Z.; BASTOS, H. CÉZAR DO NASCIMETNO. PRINCIPAIS PATOLOGIAS EM ESTRUTURAS DE CONCRETO DE PONTES E VIADUTOS: MANUSEIO E MANUTENÇÃO DAS OBRAS DE ARTE ESPECIAIS. Revista CONSTUINDO, Belo Horizonte, v. 9, Ed. Esp. de Patologia, p. 93 - 101, 2017

PERDRIX, M. DEL CARMEN ANDRADE. Manual para diagnóstico de obras deterioradas por corrosão de armaduras. São Paulo, SP: Pini, 1992. 104 p. ISBN 8572660119.

SOUZA, M. FERREIRA DE. Patologias Ocasionadas pela Umidade nas Edificações. 2008. 64 f. TCC (Graduação) Curso de Engenharia Civil, Universidade Federal de Minas Gerais, Belo Horizonte, 2008. Disponível em: $<$ http://pos.demc.ufmg.br/novocecc/trabalhos/pg1/Patologias\%20Ocasionadas\%20Pela\%20Umidade\%20Nas.pdf $>$. Acesso em: 30 out. 2018.

SOUZA, V. C.; RIPPER, T. Patologia, recuperação e reforço de estruturas de concreto. São Paulo: Pini, 1998.

TÉCHNE, Biodeterioração de concretos e argamassas. São Paulo, v. 157, n. 1, p.1-2, abr. 2010. Disponível em: $<$ http://techne17.pini.com.br/engenharia-civil/157/biodeterioracao-de-concretos-e-argamassas-285799-1.aspx $>$. Acesso em: 30 out. 2018.

TRINDADE, D. DOS SANTOS DE. Patologias em Estruturas de Concreto Armado. 2015. 88 f. TCC (Graduação) Curso de Engenharia Civil, Universidade Federal de Santa Maria, Rio Grande do Sul, 2015. Disponível em: $<$ http://coral.ufsm.br/engcivil/images/PDF/2_2015/TCC_DIEGO\%20DOS\%20SANTOS\%20DA\%20TRINDADE.pdf> . Acesso em: 30 out. 2018.

VERÇOZA, Ê. J. Patologia das edificações. São Paulo, SP: Pini, 1991. ISBN 8524102942. 